

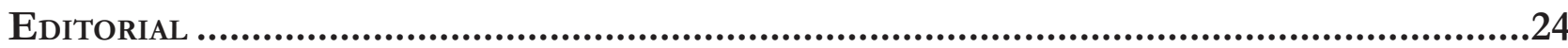

O Direito na fronteira da razão: Psicologia, neurociência e economia comportamental................... 24 Patrícia Perrone Campos Mello e Sergio Nojiri

I. NeURodireito: COGNIÇão, EMOÇÃo, JUÍZOS MORAIS E CIÊNCIA ..........................................26

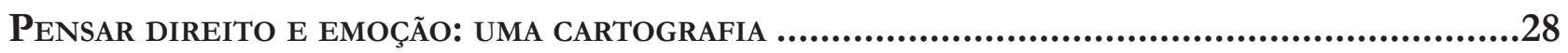

Nevita Maria Pessoa de Aquino Franca Luna

Neurodireito: o início, o fim E O MEIO

Carlos Marden e Leonardo Martins Wykrota

ENSAIO JURÍDICO SOBRE A RACIONALIDADE HUMANA: MAIORES, CAPAZES E IRRACIONAIS

André Perin Schmidt Neto e Eugênio Facchini Neto

DIVERGÊNCIAS DE PRINCÍPIO: ARGUMENTOS JURÍDICOS E MORAIS EM UM CENÁRIO DE DESACORDOS SOCIAIS

André Matos de Almeida Oliveira, Pâmela de Rezende Côrtes e Leonardo Martins Wykrota

CONSILIÊNCIA E A POSSIBILIDADE DO NEURODIREITO: DA DESCONFIANÇA À RECONCILIAÇÃO DISCIPLINAR.....

Thaís de Bessa Gontijo de Oliveira e Renato César Cardoso

MODELOS DE MORALIDADE

Molly J. Crockett

A INFELIZ BUSCA POR FELICIDADE No DiREITo

Úrsula Simões da Costa Cunha Vasconcellost, Noel Struchiner e Ivar Hannikainen

Além da liberdade: PersPeCtivas Em Nietzsche.

Lucas Costa de Oliveira

A mediaÇão de CONFlitos SOb a PERSPECTIVA do DESENVOLVIMENTO HUMANO: AS CONTRIBUIÇÕES DA PSICOLOGIA POSITIVA

Simone de Biazzi Ávila Batista da Silveira e Deise Brião Ferraz

Neuroimagiologia e aValiação de ResPonsabilidade

Nicole A. Vincent 
ANÁLISE CRÍTICA DA ORIENTAÇÃO DE CIDADÃOS COMO MÉTODO PARA OTIMIZAR DECISÕES PÚBLICAS POR MEIO DA TÉCNICA NUDGE.

Luciana Cristina Souza. Karen Tobias França Ramos e Sônia Carolina Romão Viana Perdigão

Políticas públicas e o deVer de monitoramento: “LEVANdo os Direitos A SÉrio". .252 Ana Paula de Barcellos

Nudges E POLÍticas PÚblicas: uM MECANISMO DE COMBATE AO TRABALHO EM CONDIÇÃo ANÁLOGA À DE ESCRAVO .267

Amanda Carolina Souza Silva, Débhora Renata Nunes Rodrigues e Saul Duarte Tibaldi

REDUZINDO A TRIBUTAÇÃO COGNITIVA: LIÇÕES COMPORTAMENTAIS PARA A DIMINUIÇÃO DOS EFEITOS PSICOLÓGICOS ADVERSOS DA POBREZA.............................................................288 Leandro Novais e Silva, Luiz Felipe Drummond Teixeira, Gabriel Salgueiro Soares e Otávio Augusto Andrade Santos

Políticas PÚBLICAS EM SUICÍDIO: DO PATERNALISMO CLÁSSICO AO PATERNALISMO LIBERTÁRIO E NUDGING

Davi de Paiva Costa Tangerino, Gabriel Cabral e Henrique Olive

Nudges COMO POLÍticA PÚbliCA PARA AUMENTAR O ESCASSO NÚMERO DE DOADORES DE ÓRGÃos PARA TRANSPLANTE

Roberta Marina Cioatto e Adriana de Alencar Gomes Pinheiro

Os PROGRAMAS DE INTEGRIDADE PARA CONTRATAÇÃO COM A ADMINISTRAÇÃO PÚBLICA ESTADUAL: NUDGE OU OBRIGAÇÃo LEGAL? UM OLHAR SOBRE AS DUAS PERSPECTIVAS .386

Cíntia Muniz Rebouças de Alencar Araripe e Raquel Cavalcanti Ramos Machado

Paternalismo libertário e Proteção JURídica do AMbiente: POR QUe PROTEger o AMBIENTE TAMBÉM DEVE SER PROTEGER AS LIBERDADES?

Mariana Carvalho Victor Coelho e Patryck de Araujo Ayala

Políticas públicas baseadas EM EVIdÊNCIAS COMPORTAMENTAIS: REFLEXões A PARTIR do Projeto de Lei 488/2017 do Senado

Pâmela de Rezende Côrtes, André Matos de Almeida Oliveira e Fabiano Teodoro de Rezende Lara

III. ECONOMIA COMPORTAMENTAL: VIESES COGNITIVOS E POLÍTICAS PÚBLICAS .455

ECONOMIA COMPORTAMENTAL E DIREITO: A RACIONALIDADE EM MUDANÇA Marcia Carla Pereira Ribeiro e Victor Hugo Domingues

VIESES COGNITIVOS E DESENHO DE POLÍTICAS PÚBLICAS 
A neurociênCia da moralidade na tomada de DeCisões Jurídicas Complexas e No DESENHO DE POLÍTICAS PÚBLICAS

Erik Navarro Wolkart

Desvio de CARÁter ou SIMPLESMENTE HUMANO? ECONOMIA COMPORTAMENTAL APLICADA AO COMPORTAMENTO DESONESTO

Diana Orghian, Gabriel Cabral, André Pinto e Alessandra Fontana

Políticas Públicas e a ConcretizaÇão de direitos sociais: TOMAdA DE DECisão, ARQUITETURA DE ESCOLHAS E EFETIVIDADE

Ana Elizabeth Neirão Reymão e Ricardo dos Santos Caçapietra

BEHAVIORAL ECONOMICS E DIREITO DO CONSUMIDOR: NOVAS PERSPECTIVAS PARA O ENFRENTAMENTO DO SUPERENDIVIDAMENTO .568

Samir Alves Daura

A EDUCAÇÃo FORMAL PARA O CONSUMO É GARANTIA PARA UMA PRESENÇA REFLETIDA DO CONSUMIDOR NO MERCADO? UMA ANÁLISE COM BASE NA BEHAVIORAL LAW AND ECONOMICS (ECONOMIA COMPORTAMENTAL) 600

Marcia Carla Pereira Ribeiro e Edson Mitsuo Tiujo

LIBET, DETERMINISMO E CONSUMO: AS INFLUÊNCIAS DO MARKETING E A RELEVÂNCIA DA DELIBERAÇÃo CONSCIENTE NA SUPERAÇÃo CONDICIONAL DE HÁBITOS DE CONSUMO PERIGOSOS616 Émilien Vilas Boas Reis e Leonardo Cordeiro de Gusmão

CiÊNCIA DO DIREITO TRIBUTÁRIO, ECONOMIA COMPORTAMENTAL E EXTRAFISCALIDADE. .640 Hugo de Brito Machado Segundo

IV. CoMportamento JUdiCiAL: INFLUÊNCIA DE FATORES EXTRAJURÍDicos .660

FATORES METAPROCESSUAIS E SUAS INFLUÊNCIAS PARA A FORMAÇÃo DA DECISÃo JUDICIAL .662 Rogério Roberto Gonçalves de Abreu, Lúcio Grassi de Gouveia e Virgínia Colares

“A VIDA COMO ELA É": COMPORTAMENTO ESTRATÉGICO NAS CORTES Patrícia Perrone Campos Mello

A COMPOSIÇÃo do ÓRGão COLEGIAdo E SEUS EFEITOS NA TOMADA DE DECISÃo .720 André Garcia Leão Reis Valadares

Das 11 ilhas ao centro do arquipélago: os superpoderes do Presidente do STF DURANTE O RECESSO JUDICIAL E FÉRIAS .741 José Mário Wanderley Gomes Neto e Flávia Danielle Santiago Lima 
RAZÃo, EMOÇÃo E DELIBERAÇÃO: AS ADEQUAÇÕES REgIMENTAIS do SUPERIOR TribUNAL DE JUSTIÇA PARA A FORMAÇÃo DE PRECEDENTES EFICAZES

Peter Panutto e Lana Olivi Chaim

Heurística de ancoragem e fiXaÇÃo de danos morais em JUizados especiais Cíveis no Rio DE JANEIRO: UMA NOVA ANÁLISE 778

Fernando Leal e Leandro Molhano Ribeiro

LA PROTECCIÓN DE LOS DERECHOS POLÍTICOS FRENTE A LAS FUNCIONES DISCIPLINARIAS DE LAS AUTORIDADES ADMINISTRATIVAS: SUBSIDIARIEDAD Y DEFERENCIA EN EL SISTEMA INTERAMERICANO DE DERECHOS HUMANOS. Jorge Ernesto Roa Roa

V. A influênCia do gÊNERo no PROCESSO DECisório JUdiCial

Como os Juízes decidem os Casos de estupro? ANALISANDo SENTENÇAS SOb A PERSPECTIVA DE VIESES E ESTEREÓTIPOS DE GÊNERO 826 Gabriela Perissinotto de Almeida e Sérgio Nojiri

GÊNERO E COMPORTAMENTO JUDICIAL NO SUPREMO TRIBUNAL FEDERAL: OS MINISTROS CONFIAM MENOS EM RELATORAS MULHERES?

Juliana Cesario Alvim Gomes, Rafaela Nogueira e Diego Werneck Arguelhes

Hércules, Hermes e a pequena sereia: Uma reflexão sobre estereótipos de gênero, SUbPRESENTAÇÃo DAS MULHERES NOS TRIBUNAIS E (I)LEGITIMIDADE DEMOCRÁTICA DO PODER JUDICIÁRIO .878 Jane Reis Gonçalves Pereira e Renan Medeiros de Oliveira

Prisão Cautelar de gestantes: análise do Fundamento filosófico da decisão do Habeas CoRpus N. 143.641 912

Artur César Souza e Giovania Tatibana de Souza

VI. Neurodireito APlicado ao direito E Ao Processo PENAL....................................926

CÉREbros QUe PUNEM: UMA REVISÃo CRÍTICA DA NEURoCIÊNCIA DA PUNIÇÃo .....................928 Ricardo de Lins e Horta

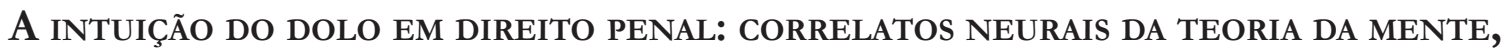
RACIOCÍNIO INDUTIVO E A GARANTIA DA CONVICÇÃO JUSTIFICADA. .946 Thiago Dias de Matos Diniz e Renato César Cardoso

As COMUNIDADES EPISTÊMICAS PENAIS E A PRODUÇÃo LEGISLATIVA EM MATÉRIA CRIMINAL..... 961 Stéphane Enguéléguélé 
DELINQUÊNCIA JUVENIL: RELAÇÕES ENTRE DESENVOLVIMENTO, FUNÇÕES EXECUTIVAS E COMPORTAMENTO SOCIAL NA ADOLESCÊNCIA

André Vilela Komatsu, Rafaelle CS Costa e Marina Rezende Bazon

Límites TEMPORALES A LAS PENAS PRIVATIVAS DE LIBERTAD ATENDIENDO AL DESARROLLO PSICOSOCIAL.

Silvio Cuneo

NEUROLAW E AS PERSPECTIVAS PARA UMA ANÁLISE OBJETIVA DO COMPORTAMENTO SUGESTIONADO: REPERCUSSÃO DAS FALSAS MEMÓRIAS NA ESFERA PENAL

Mariana Dionísio de Andrade, Marina Andrade Cartaxo e Rafael Gonçalves Mota

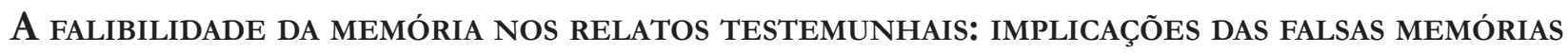
NO CONTEXTO DOS CRIMES CONTRA A DIGNIDADE SEXUAL 1036

Caroline Navas Viana

A (IR)REPETIBILIDADE dA PROVA PENAL DEPENDENTE DA MEMÓRIA: UMA DisCUSSÃo COM BASE NA PSICOLOGIA DO TESTEMUNHO. 1058

William Weber Cecconello, Gustavo Noronha de Avila e Lilian Milnitsky Stein 


\title{
Límites temporales a las penas privativas de libertad atendiendo al desarrollo psicosocial*
}

\author{
Time limits on custodial sentences in the \\ light of psychosocial development
}

Silvio Cuneo**

\section{Resumen}

Este artículo analiza la posible compatibilidad de las penas privativas de libertad perpetuas o muy extensas con las diversas teorías sobre el fin de la pena. En las conclusiones se descarta que desde las teorías absolutas o retributivas se pueda justificar la cadena perpetua o una pena muy extensa por dos motivos: Primero porque reprochar un comportamiento humano supone el reconocimiento de la categoría de persona del condenado, por ende, deben rechazarse todas las condenas que traten al condenado como no-persona, entendiendo que el reconocimiento de la dignidad humana y el respeto por los derechos fundamentales no puede restringirse a una categoría de seres humanos. En segundo lugar, porque la retribución mira al Yo, a la identidad personal del sujeto, la que con el tiempo cambia. En este punto -central para esta investigación- se le dará especial importancia, a la hora de justificar y limitar la aplicación de las penas, a las etapas del desarrollo psicosocial de la persona humana.

Palabras clave: Penas privativas de la libertad. Cadena perpetua. Prevención general. Prevención especial. Retribución. Etapas del desarrollo psicosocial.

\section{Abstract}

This article analyses the possible compatibility between life or very long terms imprisonment sentence and the various theories regarding the end of the sentence.

In the conclusion it will be excluded the possibility of justifying life im-

* Recebido em 24/06/2018 Aprovado em 12/07/2018

** Coordinador del Centro de Investigaciones Criminológicas de la Justicia Penal de la UniversidadCentral de Chile. Doctoren Derecho por la Universitat Pompeu Fabra y por la Universitá degli Studi di Trento. Autor de libros: 'Cárceles y Pobreza. Distorsiones del populismo penal' (2018), 'El Encarcelamiento Masivo' (2017), 'La cárcel moderna. Una crítica necesaria' (2017), 'Cine y Derecho penal (2010). Email: silviocuneo@hotmail.com prisonment or a very long sentence on the basis of absolute or retributive theory on two grounds: firstly, because reproaching human behaviour implies the knowledge of the type of person of the convicted, therefore, all convictions that treat the persecuted as a non-person must be rejected, on the understanding that recognition of human dignity and respect for fundamental rights cannot be restricted to a category of human beings. Secondly, because retribution looks at the "Self", at the personal identity of the subject, which changes with time. At this point - key to this research - special importance will be given to the stages of the psycho-social development of the human person when justifying and limiting the application of sentences. 
Keywords: Prison sentences. Life sentence. General prevention. Special prevention. Retribution. Stages of psycho-social development.

\section{INTRODUCCIÓN}

Este artículo busca responder a la pregunta de si se pueden justificar, siguiendo criterios de justicia y utilidad, penas privativas de libertad perpetuas o muy extensas - de más de 10 años, por ejemplo- o si, por el contrario, las penas privativas de la libertad deben tener un límite temporal, y en caso de tenerlo, cuál debiera ser dicho límite.

Para responder a la interrogante planteada, argumentaré sobre cuáles debieran ser los fundamentos y los límites de las penas en un Estado democrático de derecho respetuoso de la dignidad humana.

Partiendo de la base de que ni la pena capital ni la tortura son compatibles con el respeto por la dignidad humana, tampoco debieran la cadena perpetua (que es tortura y pena de muerte) y otras penas extensas, imponerse sin vulnerar la dignidad del condenado. La posibilidad de concebir no-personas a las que es dable aplicar un Derecho penal de enemigos es incompatible con una concepción liberal, de ultima ratio, del Derecho penal.

Tras preguntarme por la compatibilidad de las teorías sobre el fin de la pena con la cadena perpetua, y otras penas privativas de libertad extensas, este trabajo concluye que desde algunas teorías relativas o utilitarias la justificación vendrá dada por datos fácticos que verifiquen el cumplimiento de los fines esperados. Con las teorías absolutas o de la justicia, en cambio, la cadena perpetua y las penas excesivamente extensas, no resultan compatibles. Esto principalmente por dos razones: Por una parte, porque las teorías absolutas conciben a los delincuentes como personas responsables de sus actos y, en consecuencia, deben tratarlos como tales a la hora de juzgarlos, condenarlos y en todo momento en el que cumplan la pena, por lo que resultan incompatibles penas que deshumanicen al condenado. Por otra parte la retribución a la hora de sancionar mira al Yo, a la identidad del sujeto, la que con el tiempo cambia, lo que necesariamente supone que en un momento dado ya no sea posible retribuirle la culpa a un sujeto por un delito perpetrado después de tanto tiempo. Para poder explicar los cambios de la identidad del sujeto, y sus posibles efectos limitantes de una sanción retributiva, se analizarán estudios sobre las etapas del desarrollo psicosocial de la persona humana.

Antes de pasar a revisar el asunto central de este trabajo conviene recordar que si es que el estudio del Derecho penal cumple alguna función importante, ésta no puede ser otra que la contención del poder punitivo, o al menos un desenmascaramiento del funcionalismo con que opera. Sólo en cumplimiento de su función contenedora es posible hablar de Derecho penal en lugar de puro poder punitivo o, expresado con otras palabras, el Derecho penal se humaniza cuando limita el poder punitivo, y la humanización del Derecho penal se traduce en la concepción de ciudadanos, y no de súbditos, a los que protege de las garras del poder punitivo.

En esto, el discurso debe ser consecuente erga omnes, y debe ser cuidadoso en no dejar la válvula abierta al poder punitivo (que debe ser siempre limitado). De lo contrario, esta válvula permanecerá abierta y terminará centrándose y persiguiendo, como siempre, a los más desposeídos.

A continuación, en la segunda parte de este trabajo, se realizarán algunas interrogantes, las que se irán desarrollando en la tercera parte, para luego plantear las conclusiones. 


\section{INTERROGANTES EN TORNO A LA CADENA PERPETUA Y A LA EXTENSIÓN DE LAS PENAS PRIVATIVAS DE LA LIBERTAD}

La cadena perpetua y las penas privativas de libertad de extensa duración son cuestionables tanto por los devastadores efectos que generan en los penados ${ }^{1}$ como por los elevados costos que significa su mantención en las sociedades actuales. Al respecto surgen diversas interrogantes sobre las que espero dar luces para una mejor comprensión:

¿Cabe en una sociedad democrática una pena que suprime al penado? ¿Es la cadena perpetua un residuo de sociedades bárbaras? ¿Son menos democráticos los Estados que la contemplan como sanción? ¿Se puede justificar la cadena perpetua a la luz de alguna teoría sobre el fin de la pena? ¿Satisface el presidio perpetuo los requerimientos utilitarios de la prevención general y especial? ¿Puede justificarse desde una perspectiva retribucionista? ¿Es compatible con el reconocimiento de la dignidad humana?

No existen estudios empíricos que demuestren que las cárceles puedan disminuir delitos; antes bien, se ha demostrado que o los dejan inalterados o los aumentan, ${ }^{2}$ por lo mismo, es dable preguntarse cómo puede compatibilizarse la cadena perpetua con la idea de reeducación.

Por otra parte, si no resulta posible condenar a nadie a perpetuidad, ¿qué hacemos con aquellos delincuentes que no pueden reinsertarse? ¿Es, en la realidad penitenciaria, distinta la pena que la medida de seguridad?

Además, si las teorías del tratamiento reeducador han fracasado e incluso se ha demostrado que la cárcel es criminógena, impulsa la reincidencia y genera un estigma social etiquetando al delincuente, ${ }^{3}$ ¿influirán estos estudios empíricos en cómo debemos justificar las penas?

\section{Compatibilidad entre la cadena perpetua (U otras penas privativas de libertad EXCESIVAMENTE LARGAS) Y LAS TEORÍAS SOBRE EL FIN DE LA PENA}

A continuación intentaré responder a la pregunta de si la cadena perpetua puede justificarse según las diversas teorías sobre el fin de la pena. Partiré analizando las teorías relativas o preventivas (la pena útil) y luego las absolutas o retributivas (la pena justa). No examinaré las teorías mixtas, las que creo no pasan de ser una yuxtaposición de doctrinas absolutas y relativas. Para éstas, la justificación de la cadena perpetua puede ser mucho más estricta, porque requiere que se justifique desde una perspectiva absoluta y relativa, como lo

1 Sobre los efectos de las penas privativas de libertad, los estudios de campo se remontan a los años cuarenta del pasado Siglo. Sobre esto véanse: CLEMMER, D. The prision community, Nueva York: Holt, Rinehart and Winston, 1958. (Originalmente publicado en 1940). GOFFMAN, Erving. Internados: ensayos sobre la situación social de los enfermos mentales. Traducción de María Oyuela. Buenos Aires: Talleres Gráficos Color Efe, 1992. (Originalmente publicado en 1961). Para estudios más recientes, véanse: GOZZANO, M. Compendio di psichiatria clinica e criminológica. Turín: Rosenberg \& Sellier, 1971. p. 240-246; LIEBLING, A.; MARUNA, S. (Ed.). The effects of imprissonment. Londres: Willan Publishing, 2005. p. 3.

2 Sobre el particular, véase: Cid Moliné, J., ¿Es la prisión criminógena?: un análisis comparativo de reincidencia entre la pena de prisión y la suspensión de la pena, en Jueces penales y penas en España, Valencia: Tirant lo Blanch, 2002.

3 Sobre la teoría del etiquetamiento o Labeling Approach puede consultarse LARRAURI, E. ¿Para qué sirve la criminología?. Cuadernos de Derecho Judicial - CJPG, Madrid, Política Criminal, 1999. p. 8.

Esta teoría, basada en el inteaccionismo simbólico, significó un cambio de paradigma en el estudio de la desviación, alejándose íntegramente de la sociología que la precedía, que entendía el control social como una respuesta a la desviación (véase: LARRAURI, E. La herencia de la criminología crítica. 2. ed. México: Siglo XXI,1992. p. 28). El Labeling Approach plantea una idea diametralmente opuesta a las que la precedían, al entender que la desviación es una respuesta al control social. Bajo la vieja idea de que la persona deviene en lo que se dice que es, la teoría del etiquetamiento colegirá que quien es tratado (etiquetado) de delincuente será más propenso a delinquir que quién no ha sido etiquetado como tal (véase, TANNENBAUM, F. Crime and the community. New: Nueva York, 1938. p.19). 
hace Roxin, ${ }^{4}$ o bien puede consistir en la combinación de criterios de fundamentación absolutos y relativos. Tampoco me detendré en las teorías negativas de la pena, puesto que como ellas niegan que la pena tenga legitimación, claramente no justifican la cadena perpetua.

Si bien autores como Rafael Alcácer ${ }^{5}$ distinguen para justificar las penas criterios empíricos o instrumentales de aquéllos valorativos o ético-políticos, para mí esta diferenciación no tendría gran importancia, porque respecto de las teorías relativas o preventivas, que buscan generar algún efecto en el futuro y no suponen una desvaloración de un acto pasado, bastaría la comprobación empírica de eficacia de la pena para justificar o no una sanción. Por ejemplo, si un drástico aumento de penas para el delito de manejo en estado de ebriedad logra demostrar empíricamente que éste se reduce, se podría decir que, desde una perspectiva preventivo-general -y quizá también especial-, dicha sanción encuentra justificación. Por otro lado, si tras un estudio empírico es posible concluir que la pena de muerte no logró disminuir los delitos de violación u homicidio, dicha sanción, desde criterios preventivo-generales, no podría justificarse, pero sí desde criterios de prevención especial negativa, ya que el condenado a muerte no podrá seguir perpetrando delitos. En conclusión, respecto de la prevención, como ésta no supone un desvalor de una conducta del pasado, sino sólo un instrumento tendiente a la evitación de delitos futuros, o como su nombre lo indica, a prevenir delitos, carece de sentido preguntarnos por alguna legitimación o justificación que diga relación con valores. Por otro lado, en el caso de la retribución, consistiendo ésta en una desaprobación, en una desvaloración pública que se concreta en la pena, sí tiene sentido hablar de justificación valorativa o ético-política, puesto que la retribución se mueve en el mundo de los valores.

\subsection{Las teorías relativas}

\section{a) La prevención general}

Para la prevención general (positiva y negativa) la cadena perpetua se puede justificar sólo si se comprueba empíricamente que ésta previene delitos. Esta formulación choca con dos problemas prácticos. Por una parte, parece difícil dicha compatibilización porque la experiencia demuestra que crímenes castigados durante largos períodos de tiempo con penas severas se siguen cometiendo, lo que hace difícil conciliar cualquier pena con la prevención general. Y, por otro lado, resulta difícil saber si es la pena la que genera el efecto preventivo o si, más bien, la mayoría de las personas no suelen cometer delitos no por temor a una pena, sino por otro tipo de consideraciones de carácter ético. Si bien la prevención general no parece encontrar impedimentos axiológicos para justificar y defender la cadena perpetua, sí parece difícil demostrar que esta sanción consiga los efectos esperados.

Ya desde Beccaria se viene diciendo que la prevención de los delitos se consigue más por la certeza de la pena que por su severidad. Entonces, si el marqués lombardo tiene razón, parece complejo otorgarle legitimidad a la cadena perpetua, al menos desde la prevención general. ${ }^{6}$ En este mismo sentido, para Silva Sánchez

mientras los incrementos en la severidad de las penas no tienen efectos preventivos comprobados, éstos si resultan del reforzamiento de los factores que inciden en una mayor certeza de la sanción (...) si el aumento de la certeza de las sanciones penales (y por tanto, en general, el aumento de la certeza de que el sistema penal funcionará satisfactoriamente) supone incrementos verificables en la eficacia

4 ROXIN, C. Derecho penal parte general: fundamentos: la estructura de la teoría del delito. Traducción de la $2^{\mathrm{a}}$ edición alemana y notas por D. M. Luzón Peña, M. Díaz y García Conlledo y J. de Vicente Remesal. Madrid: Civitas, 1997. t. 1.

5 ALCÁCER GUIRAO, R. Los fines del Derecho penal: una aproximación desde la filosofía política. Anuario de Derecho penal y Ciencias penales (LI). Disponible em: < http://vlex.com/vid/fines-aproximacion-filosofia-politica-383186>. 1998. p. 378.

6 La afirmación de que el Derecho penal no intimida ha sido sostenida por varios autores. Para Muñoz Conde, "[e]n ningún caso se puede aceptar [...] que las leyes penales cooperan productivamente en el aumento o en la disminución de la criminalidad" en: MUÑOZ CONDE, F. Derecho penal y control social. Santa Fe de Bogotá: Editorial Temis, 1999. p. 125; para Bustos y Hormazábal, los efectos preventivo-generales no serían comprobables empíricamente, en: BUSTOS, J.; HORMAZÁBAL, H. Lecciones de derecho penal. Madrid: Editorial Trotta, 1997. v. 1 
preventiva de las normas, ello es indicativo de que el Derecho penal en su conjunto intimida más de lo que intimidaría su ausencia. ${ }^{78}$

El principal problema de la justificación empírica de la cadena perpetua radica en que dicha pena sólo se ha aplicado respecto de delitos de gran gravedad, y precisamente los autores de estos delitos son normalmente difíciles de amedrentar; por ende, la amenaza intimidatoria difícilmente producirá los efectos buscados por esta pena. Paradójicamente sería posible concluir que la cadena perpetua sería justificable, desde la prevención general, si se castigara con esta pena el manejo en estado de ebriedad o algún delito de cuello blanco. En cambio, parece difícil justificarla respecto de violaciones y asesinatos.

Tampoco me atrevo a afirmar que con esta pena se aseguren los fines de paz social buscados o queridos por la prevención general positiva, aunque podría argumentarse que esto sí se produce basado en antecedentes concretos. $\mathrm{Al}$ respecto desconozco estudios empíricos que puedan acreditar esta eficacia preventivo general positiva y no me imagino cómo podrían elaborarse. En conclusión, creo que la cadena perpetua no podría justificarse en base a criterios de prevención general negativa y no tengo una respuesta categórica respecto a su modalidad positiva.

b) La prevención especial

En principio, la prevención especial negativa sí podría justificarse la cadena perpetua, porque el sujeto encarcelado no podrá perpetrar delitos contra la comunidad libre. Sin embargo, como se habrá advertido de la afirmación anterior, esto supone desconocer la dignidad de las personas privadas de libertad, ya que su seguridad valdría nada o menos que la de quienes se encuentran en libertad. Lo único que se puede esperar de una pena privativa de libertad, de corta o de larga duración, es que los internos no puedan perpetrar delitos en la comunidad libre, pues, como observa Hentig,

[n] umerosos delitos se producen en las cárceles, desde los comunes atentados contra la propiedad, hasta falsificaciones documentales y de moneda, extorsiones, tráfico ilegal de alcohol y estupefacientes, violaciones, riñas y, desde luego, homicidios. ${ }^{9}$

Hoy, además, se cometen múltiples delitos desde dentro de las cárceles hacia la comunidad libre, por ejemplo, estafas telefónicas, falsificación de moneda, tráfico de drogas, etc. Asimismo, grupos de crimen organizado, mafias y narcotraficantes, suelen reclutar a sus soldados en las prisiones, los que, una vez libres, y por falta de otras oportunidades, entran rápidamente a las filas de estos grupos organizados. En estas circunstancias parece quimérico afirmar que la privación de libertad significa que el interno no cometerá delitos.

Las cárceles distan mucho de ser un lugar donde se cumple una pena sólo privativa de libertad en la que sus presos conviven sin perpetrar crímenes preparándose para la tan anhelada reinserción social. Antes bien, todo lo contrario: los niveles de violencia y la constante comisión de delitos en la mayoría de las cárceles son muy superiores que en la comunidad libre. Sin embargo, es claro que al menos respecto de la sociedad libre las posibilidades de perpetrar delitos desde la cárcel son muy inferiores en relación con las que tiene un

7 SILVA SÁNCHEZ, J. Aproximación al derecho penal contemporâneo. 2. ed. ampliada y actualizada. Buenos Aires: B de F, 2010. p. 252. 8 Diversos estudios han demostrado que más importante que la gravedad de la sanción lo es su probabilidad. Sobre el particular: LIEBERMAN, David. Learning, behavior, and cognition: Wadsworth. Belmont: Publishing, 1993; AZRAN, N.; HOLZ, W. C.; HAKE, D. F. Fixed ratio punishment. Experimental Analysis of Behavior, 6. 1963. Disponible en: <http://www.ncbi.nlm.nih.gov/pmc/articles/PMC1404287/pdf/jeabehav00187-0003.pdf.>.; LANDE, S. An irresponsive time analysis of variable-ratio punishment. Journal of Experimental Analysis of Behavior, 35, 1981; entre otros. Otro factor importante disuasivo lo constituye la dilación, en el sentido que una sanción próxima a la perpetración de un delito puede ser más disuasiva que una más grave si es más inmediata. Al respecto: Solomon, R., TURNER, L. H. Y; LESSAC, M. S. Some effects of delay of punishment on resistence to temptation in dos. Journal of Personality and Social Psychology, 8, 1968 y LOEWENSTEIN, G., Out of control: visceral influences of behavior. Organizational Behavior and Human Decision Processes, 65, 1996. Sobre el estudio de Solomon, Turner y Lessac, hay que ser sumamente cautos puesto que no nos parece que puedan ser comparables las reacciones de los animales sancionados con las de personas sancionadas. Resulta difícil, si no imposible, que un perro entienda perfectamente el porqué de una sanción por algo que hizo hace una semana. En cambio, creemos que un hombre puede entender el porqué de una sanción aplicada meses e incluso años después de la perpetración de su delito. 9 HENTIG, H. La pena. Traducción castellana y notas por José María Rodríguez Devesa. Madrid: Editorial Espasa Calpe, 1967. p. 376-381. t. 2 
sujeto en libertad. Por ende, si esta teoría es capaz de desconocer la dignidad o la calidad de personas de los presos, bien podría justificarse para éstas la cadena perpetua. ${ }^{10}$

Para la prevención especial positiva, la cadena perpetua podría justificarse sólo si consideramos que existen sujetos cuya resocialización es imposible. Es decir, esta teoría justificaría la cadena perpetua sólo respecto de los delincuentes incorregibles, ${ }^{11}$ utilizando la denominación de Von Liszt y de Ferri. Es decir, para que esta teoría, que profesa la resocialización, pueda justificar la pena perpetua (o una pena privativa de libertad muy extensa), es necesario que crea en la existencia de seres inferiores a los que es necesario separar de la convivencia social.

Un último problema práctico para la prevención especial (tanto negativa como positiva) se genera porque en las sociedades modernas la privación de libertad es la pena más grave que se puede aplicar. Entonces, un condenado a ésta ya no podría recibir más pena. Por ende, sus posteriores delitos no podrían ser sancionados, lo que significa que podrá perpetrarlos con completa impunidad.

\subsection{La retribución}

Para la retribución la cadena perpetua no puede justificarse, y esto por dos motivos vinculados entre sí. En primer lugar, porque si la retribución, como desvaloración, concibe a los delincuentes como personas responsables de sus actos, debe seguir tratándolas como tales a la hora de condenarlas y en todo momento en el que cumplan la pena. Es decir, para la retribución los delincuentes son personas porque responden de sus actos y al momento de responder, esto es, al cumplir la pena, siguen siendo personas, por lo que quedan fuera penas que deshumanicen al condenado. El segundo motivo por el que pensamos que la retribución no puede justificar la cadena perpetua es porque la retribución a la hora de sancionar mira al Yo, a la identidad del sujeto, la que, con el tiempo, cambia, lo que necesariamente supone que en un momento ya no podremos retribuirle la culpa a un sujeto por un delito perpetrado hace tanto tiempo. Partiremos analizando el primero de los motivos y reservaremos para el final la argumentación acerca del cambio de la identidad del sujeto por el paso del tiempo.

a) La retribución necesariamente lleva a una concepción de un Derecho penal antropológicamente fundado, un Derecho penal de hombre y para hombres, ${ }^{12}$ en el que no puede dejar de verse en el condenado

10 La reserva de la categoría de persona sólo para algunos seres humanos ha sido defendida por diversos autores que, de una u otra manera, han legitimado un poder punitivo de carácter totalitario o con incrustaciones de corte autoritario. Por ejemplo, Carl Schmitt como jurista del nacionalsocialismo y defensor del Estado absoluto participó en la creación de leyes tendientes a purificar al III Reich de la contaminación judía; o Günther Jakobs, para quien "un individuo que no admite ser obligado a entrar en un estado de ciudadanía no puede disfrutar de los beneficios del concepto de persona”, en JAKOBS, G. Derecho penal del enemigo. Traducción de Manuel Cancio Meliá. Madrid: Civitas, 2003. p. 40. Tales concepciones, aunque se autodenominen "meramente descriptivas" y que ostenten asepsia científica abundan en la historia del Derecho penal y han contribuido a " $[\mathrm{t}]$ omar con naturalidad y hasta considerar revolucionarias la esterilización y la castración como medidas de policía preventiva, la profusión de penas de muerte, la ejecución de adolescentes, considerar delito la relación sexual con judíos o negros, los campos de concentración incluso para quienes no cometieron ningún delito", etc., en ZAFFARONI, R. Introducción al libro: Grispigni, Filippo y Mezger, Edmund la reforma penal nacionalsocialista. Buenos Aires: Ediar, 2009. p. 10. En el mismo sentido, observa MUNOZZ CONDE que: "Grispigni describe la decidida aceptación en los textos jurídico-penales nacionalsocialistas de sanciones tales como la esterilización de enfermos con enfermedades hereditarias, asociales, alcohólicos, etc.; la castración de delincuentes sexuales peligrosos; y la aplicación a menores de edad peligrosos de penas previstas para delincuentes adultos, incluso la pena de muerte. Y describe y entiende esas reformas como la consecuencia de una concepción del derecho penal basado en la idea de peligrosidad y que no tiene otra misión que la defensa social”, en: MUNOZ CONDE, F. Apéndice al libro: Grispigni, Filippo y Mezger, Edmund la reforma penal nacional-socialista. Buenos Aires: Ediar, 2009. p. 102 y 103. El mismo Grispigni no formula ninguna expresión, ni expresa ni tácita, "contra el hecho mismo de la esterilización o castración de delincuentes o asociales como sanción criminal” en MUNOZ CONDE, F. Apéndice al libro: Grispigni, Filippo y Mezger, Edmund la reforma penal nacional-socialista. Buenos Aires: Ediar, 2009. p. 106.

11 Bien podría tratarse de sujetos indisciplinables.

12 La denominación la tomo de Rivacoba, M. Introducción al estudio de los principios cardinales de derecho penal. Direito e Ciudadania n. 6, p. 57-62, 1999. Este artículo estaba destinado a ser la introducción de un libro que se titularía Los principios cardinales del derecho penal, proyecto que quedó inconcluso tras la muerte de Rivacoba. Varias de las ideas que se plantean en esta parte del trabajo formarían parte de dicho libro, pero no llegaron a ser escritas por el autor. Las utilizo sin señalar cita, puesto que la fuente era el 
a un semejante. Por eso las penas perpetuas o extremadamente largas son inadmisibles, por su radical inhumanidad, al paso que en el concepto de retribución está inscrita la persona como fin, no como medio. Esta concepción se opone tanto a quienes proponen, justifican o legitiman planteamientos que conciban la existencia de seres humanos que no sean personas como a un pretendido Derecho penal del enemigo. ${ }^{13}$

Esta primera limitación se funda en un principio de bumanidad que concurre en toda retribución bien entendida. ${ }^{14}$ Sobre la base de la seguridad y a través de ella se llega a la humanidad, a la comunidad pura, a la convivencia, que no es sólo coexistencia. El principio de humanidad supone también un sentido solidario, individualista, que no es egoísta, y que lleva a realizar la humanidad tanto en lo colectivo como en lo individual. No se trata de una humanidad entendida como buenos sentimientos, sentimentalismo, ternura del corazón ni del lenguaje de las lágrimas, sino que de la humanidad del Derecho penal concebida en sentido objetivo. Esta humanidad, si bien tiene un sentido colectivo, culmina en un sentido individual, porque concibe al hombre como sujeto de dignidad, titular de un destino personal e intransferible, con capacidad de soñar y desplegar su actuar con una serie de posibilidades implícitas para hacer posible esa comunidad, esa convivencia.

Esto hace que lo que dé sentido al Derecho penal sea precisamente este principio de humanidad. Por esto, el Derecho penal para esta concepción liberal tiene que ser mínimo, de ultima ratio y tiene que llevar a un sentido reductivo, minimizador, que no necesariamente es abolicionista, porque efectivamente el individuo debe responder de sus actos cuando éstos ofendan de manera insoportable bienes jurídicos de valoración colectiva, pero porque debe primar el interés individual al colectivo, a la hora de penar, debe emplearse la mínima aflicción, sólo aquélla que sea indispensable.

Un Derecho penal liberal, humanizado, que se aplique a una comunidad de seres libres, librevolentes como autofines, tiene necesariamente que ser un Derecho penal reducido y fragmentario. Un Derecho penal autoritario, en cambio, no es fragmentario.

Lo menos que se puede hacer, en virtud del principio de humanidad, es rebajar las penas, descriminalizar, despenalizar, desjudicializar conductas. Hay que sacar cosas del Derecho penal y propiciar modelos de resolución de conflictos.

Sin perjuicio de lo señalado precedentemente, se debe tener presente que el proceso reductivo tiene una contrapartida, cual es la necesidad de crear nuevos delitos y nuevas penas. Sin embargo, a la hora de crear nuevos delitos, hay también que crear nuevas condenas que estén en sintonía con el principio de humanidad, penas humanas, de hombres y para hombres. Así como el abolicionismo revolucionario cuestionó la pena de muerte, hoy se debe discutir, además de la pena capital, las de privación de libertad, especialmente las de larga duración, y todas las penas que excluyan al penado.

En virtud del principio de humanidad se deben descartar penas que traten al delincuente como no-hombre, que lo excluyan, como la pena de muerte o la reclusión, que en períodos más o menos prolongados rompe con la convivencia y anula la personalidad. Una reclusión prolongada más allá de ciertos límites -15 años, por ejemplo- causa graves daños irreversibles en la personalidad. Penas de veinte o más años son, en los hechos, perpetuas, pues, aunque se vuelva a la libertad, se vuelve aniquilado.

Si bien nadie niega de plano el principio de humanidad, éste se deforma por las distintas maneras que adoptan los diversos ordenamientos. Las doctrinas preventivistas no concuerdan con este principio, pues

propio Rivacoba quien me las transmitió en clases y en amenas conversaciones.

13 Para Zaffaroni " [t] odo discurso penal que acepta o legitima la existencia de enemigos no sólo arrastra un elemento de estado absoluto, sino que implica una semilla de genocidio, y si ningún accidente detiene el curso que desencadena, su resultado final es la masacre", em ZAFFARONI, R. Introducción al libro: Grispigni, Filippo y Mezger, Edmund la reforma penal nacional-socialista. Buenos Aires: Ediar, 2009. p. 25.

14 MAYER, M. Se ocupa de la idea de bumanidad como la idea del derecho, en filosofía del derecho. Traducción de la segunda edición original por Luis Legaz Lacambra. Madrid: Editorial Labor, 1931. 
rebajan la humanidad y la dignidad del hombre, transformándolo en un mero instrumentos para fines fijados por otros. En la retribución, en cambio, se concreta la desvaloración en la pena, pero no se excluye al penado de la convivencia.

Hay que tener presente las palabras de Goethe, en el sentido de que tanto si se ha de castigar, como si se ha de tratar con dulzura debe mirarse a los hombres bumanamente, en una comunidad de seres libres y fines en sí mismos. Y ser fin en sí es ser sujeto de dignidad. El reconocimiento de la dignidad es la base para designar la igualdad, puesto que en dignidad no hay nadie más digno, somos todos igualmente dignos. En dignidad se excluyen las jerarquías. El Derecho penal que no es liberal es sólo un fenómeno de poder, es puro poder punitivo y no Derecho.

Respecto a los límites máximos que debe tener una pena privativa de libertad (necesarios para una bien entendida retribución), algunos autores se han aventurado a fijar un tiempo determinado. Así, si para Guzmán Dalbora "la exclusión irreversible y total de un sujeto de la libre relación jurídica, contradice el concepto de la pena por la culpabilidad, que se orienta a restituir esa relación", ${ }^{15}$ la pena debe limitarse y [c]omo se estima que la degradación física y psíquica ya no tiene remedio después de diez o quince años, estos son también los límites máximos recomendados para las sanciones" privativas de la libertad. ${ }^{16}$

Para Von Hirsch, que plantea una teoría del merecimiento aplicada en forma benigna, la prisión

debe estar limitada para delitos graves (fundamentalmente para delitos violentos y para los casos más graves de criminalidad de cuello blanco), y la duración de la privación de libertad para estos delitos debería ser de hasta 3 años -excepto para el homicidio, donde cinco años sería el límite normal. ${ }^{17}$

Por su parte, Kleinig, basándose no tanto en una teoría del merecimiento como en la idea de trato humano y decente a los seres humanos, propone como límite máximo una pena de 25 años. ${ }^{18}$

b) La retribución mira al Yo, a la identidad personal del sujeto, la que con el tiempo cambia. Dado lo anterior, parece pertinente una pregunta ulterior sobre la identidad personal del Yo en busca de elementos que permitan fijar límites temporales a una pena fundada en el reproche personal.

Afortunadamente,

[e]n el Derecho penal de nuestros días no se suele discutir la vigencia de un principio llamado de personalidad de las penas, según el cual la pena debe ser impuesta al sujeto considerado responsable del delito, que es quien tiene que soportarla. ${ }^{19}$

Este principio junto al de responsabilidad por el hecho propio integran el principio de culpabilidad en sentido amplio ${ }^{20}$ en base al cual sólo se puede penar al mismo sujeto que cometió el delito y que se consideró responsable tras un juicio penal. Al contrario, cuando la pena recae en un sujeto distinto al que perpetró el delito se vulnera el principio de culpabilidad. La exigencia de identidad del sujeto equipara identidad individual a identidad corporal. ${ }^{21} \mathrm{Al}$ parecer, lo que hay tras la exigencia de identidadpersonal y del principio de culpabilidad es la idea de merecimiento, esencial a toda retribución. ${ }^{22}$ Pero ¿qué es identidad personal?

15 GUZMÁN DALBORA, J. La pena y la extinción de la responsabilidad penal: primera parte. Santiago de Chile: Legal Publishing, 2008. p. 200.

16 GUZMÁN DALBORA, J. La pena y la extinción de la responsabilidad penal: primera parte. Santiago de Chile: Legal Publishing, 2008. p. 204.

17 VON HIRSCH, A. Censurar y castigar. Traducción de Elena Larrauri. Madrid: Trotta, 1998. p. 80.

18 Citado en VON HIRSCH, A. Censurar y castigar. Traducción de Elena Larrauri. Madrid: Trotta, 1998. p. 74.

19 SILVA SÁNCHEZ, J. Identidad en el tiempo y responsabilidad penal. el juicio jurisdiccional de imputación de responsabilidad y la identidad entre agente y acusado: estudios penales en homenaje a Enrique Gimbernat. Madrid: Edisofer, 2008. t. 2. p. 662.

20 SILVA SÁNCHEZ, J. Identidad en el tiempo y responsabilidad penal: el juicio jurisdiccional de imputación de responsabilidad y la identidad entre agente y acusado: estudios penales en homenaje a Enrique Gimbernat. Madrid: Edisofer, 2008. t. 2. p. 662.

21 SILVA SÁNCHEZ, J. Identidad en el tiempo y responsabilidad penal: el juicio jurisdiccional de imputación de responsabilidad y la identidad entre agente y acusado: estudios penales en homenaje a Enrique Gimbernat. Madrid: Edisofer, 2008. t. 2. p. 662.

22 En cambio las tesis preventivas bien pueden prescindir de la noción de merecimiento para conseguir los fines preventivos anhelados. 
Para contestar a esta pregunta habría que analizar, al menos, dos corrientes filosóficas. Por una parte, los empiristas o reduccionistas, quienes en base a los cambios físicos y psíquicos que experimenta el sujeto con el paso del tiempo, niegan la identidad personal de éste en distintos momentos. ${ }^{23}$ Para ellos, no pudiendo afirmarse la existencia de una identidad personal, a lo sumo podría hablarse de "mera comunidad de estados mentales sucesivos, fases o etapas personales". ${ }^{24}$ A partir de esta concepción procedería plantearse si podemos responsabilizar penalmente a un sujeto en un tiempo posterior a la comisión de un delito (en tiempo 2), entendiéndolo sucesor de ese aparentemente mismo sujeto por un delito cometido en un tiempo anterior (en tiempo 1). Como parece difícil sostener que no habría que responsabilizarlo, la pregunta más pertinente, a mi juicio, sería si a partir de algún cambio (paso de un determinado lapso de tiempo o de un hecho traumático) podríamos, o no, reducir o anular dicha imputación.

Para la otra corriente, la metafísica, sí existiría identidad personal en el sujeto en diversos momentos. Habría "una identidad personal sustancial basada en la permanencia de los componentes corporal y espiritual del sujeto $[. .$.$] se trata de una permanencia esencial". { }^{25}$ Como se comprenderá, para esta tesis ni el paso del tiempo ni hechos trascendentes cambiarían la esencia individual. Por ende, no habría ningún problema en atribuir responsabilidad por un delito pasado, aunque hayan transcurrido varios decenios, puesto que se trataría del idéntico mismo sujeto. Normalmente, para los distintos ordenamientos jurídico-penales "la identidad personal se imputa". ${ }^{26}$ Sin embargo, parece necesario limitar dicho concepto normativista, por motivos prácticos y de justicia. La doctrina penal pasa por alto que el sujeto muta y asume que el sujeto siempre es el mismo (así se imputa); los límites temporales que se establecen por el Derecho penal están más relacionados con criterios prácticos que con una supuesta mutación del yo.

Según Merkel, a los requisitos tácitos de la imputación penal pertenece la suposición de que los sujetos de actuaciones penales significativas permanecen, en el curso del tiempo, idénticos a sí mismos como personas. ${ }^{27}$ Sin embargo, para este autor en determinadas situaciones esta afirmación resulta falsa o implausible. Para tratar el problema de la identidad en el tiempo -el que según Merkel no ha sido suficientemente desarrollado por las ciencias penales- se remonta al mito griego, recogido por Plutarco, del barco de Teseo, que volvía desde Creta y al que retiraban una a una las tablas estropeadas, reemplazándolas por otras nuevas, hasta el punto que ya no conservaba ninguna de las originales. De esto surge la interrogante sobre si se trataría entonces del mismo barco después de que le han cambiado todas las tablas. Luego Merkel agrega una variante al ejemplo: un marinero recoge todas las piezas que desechan para reemplazarlas por nuevas, y construye un barco exactamente igual al de Teseo. ¿Cuál de los dos sería entonces el barco original? Para Merkel cabrían tres respuestas posibles: el primero, el segundo o ninguno, ya que no podrían ser los dos al mismo tiempo. El trasfondo de la cuestión reside en el dilema de si una vez que van cambiando las partes que componen un todo permanece la identidad.

Si trasladamos el ejemplo a los seres humanos, podemos decir que, al menos en el plano físico-biológico, las personas no conservamos ni una célula durante toda nuestra vida, pues todas están en permanente renovación. ¿Somos entonces las mismas personas después de un cierto período de tiempo o de una cierta cantidad de modificaciones? ${ }^{28}$

23 Entre los sostenedores de esta postura se encuentran Locke y Hume. Para el primero, "quienes han olvidado su delito no merecen castigo", en SILVA SÁNCHEZ, J. Identidad en el tiempo y responsabilidad penal: el juicio jurisdiccional de imputación de responsabilidad y la identidad entre agente y acusado: estudios penales en homenaje a Enrique Gimbernat. Madrid: Edisofer, 2008. t. 2. p. 666 y 680. Esta afirmación se debe a la concepción de Locke que desecha el criterio de la identidad corporal asumiendo el de la conciencia que se basa en los recuerdos. En: MERKEL, R. Personale identität und die Grenzen Strafrechtlicher Zurechnung. Juristen Zeitung n. 10, p. 505-506, 1999.

24 SILVA SÁNCHEZ, J. Identidad en el tiempo y responsabilidad penal: el juicio jurisdiccional de imputación de responsabilidad y la identidad entre agente y acusado: estudios penales en homenaje a Enrique Gimbernat. Madrid: Edisofer, 2008. t. 2. p. 666.

25 SILVA SÁNCHEZ, J. Identidad en el tiempo y responsabilidad penal: el juicio jurisdiccional de imputación de responsabilidad y la identidad entre agente y acusado: estudios penales en homenaje a Enrique Gimbernat. Madrid: Edisofer, 2008. t. 2. p. 667.

26 SILVA SÁNCHEZ, J. Identidad en el tiempo y responsabilidad penal: el juicio jurisdiccional de imputación de responsabilidad y la identidad entre agente y acusado: Estudios penales en homenaje a Enrique Gimbernat. Madrid: Edisofer, 2008. t. 2. p. 670.

27 MERKEL, R. Personale identität und die Grenzen Strafrechtlicher Zurechnung. Juristen Zeitung, n. 10, 1999 . p. 502.

28 MERKEL nos ilustra mediante la referencia a dos casos de ciencia ficción. En primer lugar, plantea el problema de la teletrans- 
Más aún, ¿qué pasa con los cambios que vamos sufriendo a nivel psicológico? ¿Alteran éstos también nuestra identidad del yo? Sobre el particular, Merkel analiza los casos de Alzheimer y los de pérdida total de la memoria. ¿Sigue siendo el mismo aquél que ha perdido toda autonomía o toda vinculación con su pasado? Y, enlazándolo con nuestra investigación, ¿`se puede sancionar a alguien que no recuerde nada de su delito? Para nosotros cobra importancia esta pregunta, además, en la fase de cumplimiento. Si el condenado pierde la memoria, ¿puede seguir cumpliendo la condena por algo que no recuerda? ¿Podemos afirmar que seguimos retribuyéndole la culpabilidad a un sujeto que no sabe por qué está cumpliendo una pena?29 30

Si entendemos que con el paso del tiempo el merecimiento, el juicio de reproche y la necesidad de pena disminuyen, procede preguntarse entonces a partir de cuándo o a partir de qué circunstancia la culpabilidad del sujeto en tiempo pasado se desvanece a tal punto que la pena no parece ser justa. ${ }^{31}$

Tanto las teorías metafísicas como las empiristas, por moverse en niveles de total abstracción, parecen no satisfacer problemas jurídico-penales del mundo real, como la aflicción del preso que sufre de soledad en su celda. Sin embargo, es posible adscribir a una teoría ecléctica entendiendo que no habría problemas para imputarle a un sujeto sus actos anteriores con ciertos límites temporales o circunstanciales; ${ }^{32}$ es decir, concebir, desde la retribución, que el sujeto debe responder por sus actos pasados, pero no de manera indefinida y perpetua.

De lo que se trata es de pensar la culpabilidad de manera dinámica, considerando que el paso del tiempo hace que la culpabilidad del sujeto deje de ser la misma culpabilidad a la que se le retribuía en el momento de la sentencia y que lo condenaba para así compensar el hecho constitutivo de delito. Se trata de una limitación de carácter estructural que entiende que carece de sentido que a alguien se le sancione por el resto de su vida o por períodos demasiado extensos.

Si bien es posible saber -o acaso sólo intuir- que el sujeto va cambiando con el tiempo, no se puede tener la certeza de si es posible afirmar que en algún momento ese sujeto ya no sea el mismo que cometió el delito. Algo podría hacernos pensar que, después de veinte años de condena, ya no se trata del mismo sujeto que perpetró el delito. Claramente no concuerdan con esta tesis ni las legislaciones norteamericanas, ni muchos tribunales de los Estados Unidos de América que condenan reiteradamente a cadena perpetua a menores de edad de entre trece y diecisiete años sin posibilidad de acceder a la libertad condicional.

portación. Una máquina almacena la información de todas nuestras células en un punto A, y la reproduce en un punto B. ¿Es la persona del punto B la misma que la que estaba en A? El segundo ejemplo responde a un caso de la vida real, llevado por el BGH en 1983 con el nombre de Sirius-Fall. Un hombre convence a una joven que ha sido elegida para transmutarse en un ser superior una vez que abandone su cuerpo actual. Si el cambio se hubiera producido, ¿`eguiría siendo la joven la misma persona que antes? MERKEL, R. Personale identität und die Grenzen Strafrechtlicher Zurechnung. Juristen Zeitung, n. 10, p. 53-505, 1999.

29 MERKEL se refiere al caso de un hombre que, luego de tener un accidente en bicicleta, sufrió una pérdida total de la memoria y comenzó a pedalear mecánicamente sin rumbo fijo, bebiendo de baños abiertos, durmiendo al descampado y sin comer. Tras una semana de incesante camino se preguntó qué estaba haciendo y no supo responderse. Merkel se pregunta: si este hombre hubiera cometido antes del accidente un delito, ¿podríamos condenarlo por él, aunque no lo recuerde? MERKEL, R. Personale identität und die Grenzen Strafrechtlicher Zurechnung. Juristen Zeitung, n. 10, p. 53-505, 1999. p. 509.

30 Si bien se trata de una situación distinta, en la que no hay pérdida de memoria, resulta interesante el caso chileno conocido como El chacal de Nabueltoro. En 1960, en la localidad de Nahueltoro (Chile), un alcohólico en estado casi de salvajismo mató a una mujer y a sus cinco hijos. Tras treinta y dos meses de cárcel, en los que el autor experimentó sorprendentes cambios de conducta, puesto que era la primera vez en su vida que convivía con más personas, aprendió el oficio de hacer guitarras, se transformó al catolicismo y se arrepintió de sus crímenes. Pese a la intervención de Eloy Parra, el sacerdote que vivió de cerca esta transformación, pidiendo reiteradamente el indulto presidencial, éste no fue otorgado por el entonces Presidente de la República Jorge Alessandri, y el chacal fue ejecutado. Esta historia fue llevada al cine por Miguel Littin con el título "El chacal de Nahueltoro" y constituye una pieza indispensable del séptimo arte latinoamericano.

31 Podría argumentarse que es el hecho el que con el paso del tiempo merece menor reproche. Sin embargo, no entraremos en esta cuestión para centrarnos especialmente en la disminución de culpabilidad del sujeto por el paso del tiempo o por el acaecimiento de circunstancias especiales.

32 Para el objeto de estudio de este artículo me centraré en los límites temporales. Circunstanciales podrían ser, por ejemplo, un contexto de guerra, una grave crisis económica o una catástrofe natural. Estas circunstancias podrían despertar en el sujeto instintos primitivos prevaleciendo los de auto conservación. 
Un estudio realizado por Amnesty International y Human Rights Watch publicado en 2005 muestra que hay, en Estados Unidos, al menos 2.225 personas cumpliendo cadena perpetua sin libertad provisional por delitos cometidos cuando eran menores de dieciocho años, la mayoría de los cuales cumple dicha pena por su primer delito. El $16 \%$ de los condenados habría perpetrado su delito cuando tenía entre trece y quince años. ${ }^{33}$

La dramática situación descrita por el informe de Amnesty International y Human Rights Watch parece difícilmente defendible desde criterios preventivos, pero en relación a lo que ahora quisiera enfatizar, esta situación resulta inaceptable para una concepción retribucionista y no sólo por la evidente inhumanidad de dichas penas, puesto que si la condena se funda en la retribución, debemos entender que seguimos retribuyéndole la culpa a lo largo de las fases del cumplimiento de la pena privativa de libertad. Sobre esto se basa la idea de que habría entonces, en algún momento, una retribución no merecida porque la culpabilidad, vinculada a la identidad personal, ha ido disminuyendo con el paso del tiempo y con el cambio de identidad del sujeto, llegando en un momento a ser tan mínima como para no poder justificar ya la pena.

Puede que tras veinte o cuarenta años quede aún un núcleo de identidad en el sujeto, pero parece que ese núcleo de identidad no es suficiente para soportar la lógica de la responsabilidad, la lógica del merecimiento, la lógica de la retribución, porque no se daría una identidad lo bastantemente fuerte entre el sujeto que cometió el delito y el que está cumpliendo la pena en un momento muy posterior. Si afirmamos que el sujeto cambia, llegando a mutar su identidad personal, llegaría un momento en que ya no es posible continuar compensando la culpabilidad porque la persona ha pasado a tener una identidad distinta

La idea aquí planteada entiende que no se puede hacer responsable a ese sujeto tras un extenso espacio de tiempo, porque ya no sería el mismo. Una condena perpetua o muy prolongada supondría un exceso de pena que no podría ser compensable con la culpabilidad, porque la culpabilidad, entendida como aquella parte del sí mismo, determinada por su propia voluntad, por su Yo que en un momento determinado ha decidido cometer un hecho delictuoso, ya no es la misma. Si esto podemos comprobarlo, habría aquí un límite a la pena privativa de libertad desde una concepción retributiva.

Aunque esta teoría parece ser sólo una intuición, ya que resulta imposible saber empíricamente si y cuándo una persona pasa a tener una identidad distinta, es posible intentar dotar a estos postulados de un carácter científico vinculándolos a estudios sobre las fases del desarrollo biológico y psicológico. ${ }^{34}$

Erik Erikson, un psicoanalista alemán (1902-1994), elaboró en Estados Unidos una teoría del desarrollo de la personalidad en la que describe ocho etapas del desarrollo psicosocial del ser humano. ${ }^{35}$ Para Erikson una persona psicológicamente sana debe pasar por cada una de esas etapas y sufrir lo propio de cada etapa y disfrutar de sus beneficios.

Las primeras cuatro etapas se relacionan con crisis y conflictos en el desarrollo de la vida hasta los trece años. Ellas son: 1.- Confianza frente a desconfianza, etapa que transcurre desde el nacimiento hasta los dieciocho meses de vida aproximadamente; 2.- Autonomía frente a vergüenza y duda, etapa que transcurre desde los dieciocho meses hasta los tres años; 3.- Iniciativa frente a sentimiento de culpa, etapa que transcurre desde los tres a los cinco años, y; 4.- Laboriosidad frente a inferioridad, etapa que va desde los cinco hasta los trece años aproximadamente.

Las cuatro etapas finales son las que más nos importan a objeto de entender una limitación de responsabilidad de carácter jurídico-penal, entendiendo que antes de los trece años carece de todo sentido atribuir algún tipo de responsabilidad penal. Esto podría responder a la admisión de que "hasta la adolescencia, el individuo no puede desarrollar los requisitos de desarrollo fisiológico, maduración mental y responsabilidad

33 Puede consultarse el informe en: <http://www.amnestyusa.org/>.

34 El Derecho penal debe escuchar a las ciencias para limitar sus efectos. La inimputabilidad de los niños o de los dementes responde a concepciones que provienen del mundo de las disciplinas causales explicativas.

35 ERIKSON, E. Identidad, juventud y crisis. Traducción de Alfredo Guéra. Madrid: Taurus Ediciones, 1980. p. 80. 
social para experimentar y atravesar la crisis de identidad". ${ }^{36}$ Pasemos a analizar las etapas que incluirían la vida desde la adolescencia hasta la senectud.

La quinta etapa o adolescencia, se caracterizaría por la existencia de un conflicto de Identidad frente a confusión de identidad. Abarcaría un período que iría aproximadamente entre los trece y los veintiún años. En esta etapa el joven busca definir una identidad propia, se trata de

un modo de vida entre la infancia y la edad adulta. Así, en los últimos años de escolaridad, los jóvenes, acosados por la revolución fisiológica de su maduración genital y ante la incertidumbre de sus roles adultos, parecen muy ocupados con caprichosas tentativas por establecer una subcultura adolescente mediante lo que tiene el aspecto de una identidad final. ${ }^{37} 38$

En la sexta etapa, el joven adulto, vive un conflicto de relación intima frente al aislamiento. Esta comprendería el período que va desde los veintiún hasta los cuarenta años aproximadamente y se caracteriza por una mayor seguridad, puesto que al parecer este joven adulto ya no necesitaría, como antes, mostrarse algo a sí mismo.

La séptima etapa, de adultez, se caracteriza por un conflicto de generatividad frente a estancamiento, e iría desde los cuarenta a los sesenta años. Esta etapa suele relacionarse con la crianza de hijos y se caracteriza por una constante preocupación por el futuro (de los hijos, de las futuras generaciones, etc.)

Por último, en la octava etapa, de senectud o madurez, surge un conflicto de integridad frente a desesperanza. Esta etapa abarcaría el período comprendido desde los sesenta años en adelante, y se caracteriza por un deterioro físico, la presencia de enfermedades, un debilitamiento muscular y la preocupación cierta por la muerte propia o de pares.

Si filosóficamente puede defenderse la idea de que el sujeto va cambiando en el tiempo, que eso afecta a la culpabilidad y que además psicosocialmente existen esas etapas que se encuentran analizadas y han sido estudiadas por la psicología, entonces parece que lo que sólo era una intuición tiene un apoyo científico que permitiría acotar la pena desde la retribución, límite que rondaría, según los estudios de Erikson, en 20 años o menos, es decir, la duración de cada etapa. ${ }^{39}$ Esto se desprende de la necesidad de que el individuo pueda vivir en libertad en cada una de las etapas, para así poder aspirar un pleno desarrollo.

Desde el punto de vista retributivo parece coherente que el mal de la pena se prolongue sólo respecto de una de las cuatro etapas: que el delito cometido en una etapa de la vida se le retribuya en la misma fase en que cometió el delito. Excepcionalmente, si el delito se comete a fines de una de las etapas, a los diecinueve años por ejemplo, podría pasar la pena a la etapa siguiente teniendo que asumir el marco de la fase sucesora. Sin embargo, parece prudente limitar la pena y que en ningún caso supere la mitad de la etapa siguiente, dejando así libre la mitad de dicho ciclo para que el sujeto pueda desarrollarse en esa nueva fase.

\section{Conclusiones}

El Derecho, en general, y especialmente el Derecho penal, deben nutrirse de diversas disciplinas para así poder aplicar sus preceptos normativos. Este trabajo, que desarrolla un cuestionamiento a las penas privati-

36 ERIKSON, E. Identidad, juventud y crisis. Traducción de Alfredo Guéra. Madrid: Taurus Ediciones, 1980. p. 78.

37 ERIKSON, E. Identidad, juventud y crisis. Traducción de Alfredo Guéra. Madrid: Taurus Ediciones, 1980. p. 110.

38 Lo planteado precedentemente (en nota 3) sobre la teoría del etiquetamiento o Labeling Approach es aún más sensible tratándose de adolescentes, quienes son más propensos a devenir en lo que se dice que son, asumiendo las etiquetas de delincuente juvenil y adecuando su comportamiento a las expectativas de la etiqueta. Véanse: LARRAURI, E. La herencia de la criminología crítica. 2 . ed. México: Siglo XXI, 1992. TANNENBAUM, F. Crime and the community. New: Nueva York, 1938.

39 Un factor distorsionador que debemos considerar, a propósito de las penas privativas de la libertad, se encontraría en los efectos psicológicos y fisiológicos que produce el encierro en el condenado. La reclusión y la rutina mutan la percepción del tiempo, haciendo que el condenado perciba que éste pasa con más lentitud, lo que, creemos, afecta y desfigura las fases o épocas que son naturales al hombre. 
vas de la libertad perpetuas o muy extensas, dedica especial importancia a las etapas del desarrollo psicosocial como fundamento limitativo de la aplicación de las penas según concepciones de justicia o retributivas.

A la hora de verificar si es dable justificar las penas perpetuas o muy extensas, es necesario diferenciar el tipo de teoría sobre el fin de la pena que busque justificar su imposición. Así, a las teorías relativas, que defienden funciones preventivas -más que fines-, les resultan preferidos los argumentos de corte empírico. Por ende, no parece que estos planteamientos puedan ser teorías sobre el fin de la pena, ya que a éstas les es propia una connotación valorativa que no se puede encontrar en las observaciones de tipo únicamente utilitario. Por eso no nos resulta viable dar una respuesta categórica acerca de si la prevención puede o no justificar la cadena perpetua, ya que esta posible justificación dependerá de datos fácticos en los que podrá verificarse si se cumplen o no los fines esperados. Así, por ejemplo, la cadena perpetua podrá justificarse desde la prevención general negativa, si se comprueba que ésta intimida; o desde la prevención especial negativa, si se verifica que con ésta se saca de circulación al penado, etc.

Por otra parte, sostener que la retribución se mueve en el mundo de los valores no equivale a decir que ésta deba despreciar desdeñosamente los datos de la realidad, ya que la naturaleza y la medida abstracta de la pena dependen de consideraciones históricas. La retribución, desvinculada enteramente de los efectos reales de la pena en el penado y en la sociedad, degenera en la retribución propia del idealismo hegeliano, en el sentido de que llevaría a penar porque hay que penar y punto.

De acuerdo con esta concepción de retribución, atenta a la realidad social y especialmente a los efectos que la pena produce en el penado, se descarta toda posible justificación de la cadena perpetua y de las penas de muy larga duración, por los dos motivos que fueron desarrollados precedentemente.

Quisiera ahora, para concluir estas reflexiones, esbozar mi propia propuesta de límites temporales a las penas privativas de la libertad. Ante todo, creo que se debe reservar la pena de prisión únicamente para delitos de especial gravedad, sea contra bienes individuales (asesinato, violación y otros), sea contra bienes jurídicos colectivos cuya ofensa delictuosa afecta gravemente a una multitud de personas (delitos contra el orden público y económico, principalmente). Y, para los delitos de baja y mediana gravedad, propongo el establecimiento de penas distintas a la prisión, que no se presenten en la ley como penas alternativas a la privativa de libertad, sino como pena inmediata y única de esos delitos. Si bien este asunto ha preocupado bastante a la doctrina, parece que la ciencia penal no ha desarrollado todo su poder de imaginación en la búsqueda de penas distintas de la prisión. Ante esta situación parece necesario hacer un uso más amplio y diversificado de la restricción de la libertad ambulatoria, de la inhabilitación para el ejercicio de ciertos derechos, de las penas pecuniarias y de otras formas de sanción que, respetando la dignidad del condenado, lo afecten en bienes que el hombre del siglo XXI considera importantes, pero distintos de las penas privativas de libertad.

Respecto a las penas privativas de libertad, y en atención a los daños irreversibles que produce en el condenado un encierro de más de quince años, propongo que éste sea el límite máximo de la pena privativa de libertad. Me gustaría, si pienso en genocidas o en tiranos, poder proponer un límite superior -40 años, por ejemplo. Sin embargo, no debe perderse de vista que el genocida es también persona, ya que para una teoría liberal de Derecho penal antropológicamente fundado, la sociedad se compone de personas (no de enemigos o no-personas) y se sanciona a personas (por monstruosos que puedan parecer) y, en consecuencia, no debe dejarse de ver en el penado a un semejante, quien, a la hora de ser sancionado, debe seguir siendo reconocido como sujeto de dignidad.

En relación a los estudios de Erikson citados en la tercera parte y entendiendo que de las cuatro etapas que importan para la imputación penal de responsabilidad hay una de menor duración temporal -en concreto, la adolescencia o quinta etapa, la que para Erikson comprende un período que va desde los trece a los veintiún años-, proponemos un límite de ocho años como máxima pena privativa de libertad para los delitos perpetrados por adolescentes, esto es, por personas que, a la hora de cometer el delito, tenían entre 
dieciocho ${ }^{40}$ y veintiún años.

En resumen, y para concluir lo planteado en este trabajo, creo que desde criterios retributivos o de justicia la pena no debe exceder de 15 años tratándose de autores mayores de 21 años, y una pena que no supere los 8 años para los menores de 21 años.

\section{REFERENCIAS}

ALCÁCER GUIRAO, R. Los fines del Derecho penal: una aproximación desde la filosofía política. Anuario de Derecho penal y Ciencias penales (LI). Disponible em: < http://vlex.com/vid/fines-aproximacion-filosofiapolitica-383186>. 1998.

AZRAN, N.; HOLZ, W. C.; HAKE, D. F. Fixed ratio punishment. Experimental Analysis of Behavior, 6. 1963. Disponible en: <http://www.ncbi.nlm.nih.gov/pmc/articles/PMC1404287/pdf/jeabehav00187-0003. pdf.>.

BUSTOS, J.; HORMAZÁBAL, H. Lecciones de derecho penal. Madrid: Editorial Trotta, 1997. v. 1

Cid Moliné, J., ¿Es la prisión criminógena?: un análisis comparativo de reincidencia entre la pena de prisión y la suspensión de la pena, en Jueces penales y penas en España, Valencia: Tirant lo Blanch, 2002.

CLEMMER, D. The prision community, Nueva York: Holt, Rinehart and Winston, 1958. (Originalmente publicado en 1940).

CROFTS, N. at al. Spread of bloodborne viruses among Australian prison entrants. British Medical Journal, v. 310, n. 6975, 1995.

ERIKSON, E. Identidad, juventudy crisis. Traducción de Alfredo Guéra. Madrid: Taurus Ediciones, 1980.

GOFFMAN, Erving. Internados: ensayos sobre la situación social de los enfermos mentales. Traducción de María Oyuela. Buenos Aires: Talleres Gráficos Color Efe, 1992. (Originalmente publicado en 1961).

GOZZANO, M. Compendio di psichiatria clinica e criminológica. Turín: Rosenberg \& Sellier, 1971. p. 240-246.

GUZMÁN DALBORA, J. La pena y la extinción de la responsabilidad penal: primera parte. Santiago de Chile: Legal Publishing, 2008.

HENTIG, H. La pena. Traducción castellana y notas por José María Rodríguez Devesa. Madrid: Editorial Espasa Calpe, 1967. t. 2

JAKOBS, G. Individuo y persona: sobre la imputación jurídico-penal y los resultados de la moderna investigación neurológica. En: CANCIO, Melia; FEIJOO, Sánchez (Coord.). Teoría funcional de la pena y de la culpabilidade. Madrid, 2008.

JAKOBS, G. Derecho penal del enemigo. Traducción de Manuel Cancio Meliá. Madrid: Civitas, 2003.

LANDE, S. An irresponsive time analysis of variable-ratio punishment. Journal of Experimental Analysis of Behavior, 35, 1981.

LARRAURI, E. ¿Para qué sirve la criminología?. Cuadernos de Derecho Judicial - CJPG, Madrid, Política Criminal, 1999.

LARRAURI, E. La herencia de la criminología crítica. 2. ed. México: Siglo XXI, 1992.

LIEBERMAN, David. Learning, behavior, and cognition: Wadsworth. Belmont Publishing, 1993.

40 Esto considerando que bajo los dieciséis años no debe haber imputación penal y, asimismo, entre los dieciséis y los dieciocho un régimen especial de Derecho penal con trato más suave para los menores de edad. 
LIEBLING, A.; MARUNA, S. (Ed.). The effects of imprissonment. Londres: Willan Publishing, 2005.

LOEWENSTEIN, G., Out of control: visceral influences of behavior. Organizational Behavior and Human Decision Processes, 65, 1996.

MAYER, M. Filosofía del derecho. Traducción de la segunda edición original por Luis Legaz Lacambra. Madrid: Editorial Labor, 1931.

MAYER, M. Se ocupa de la idea de bumanidad como la idea del derecho, en filosofía del derecho. Traducción de la segunda edición original por Luis Legaz Lacambra. Madrid: Editorial Labor, 1931.

MERKEL, R. Personale identität und die Grenzen Strafrechtlicher Zurechnung. Juristen Zeitung n. 10, p. 505-506, 1999.

MOLINA FERNÁNDEZ, F. ¿Culpabilidad sin libertad?. En: CANCIO, Melia; FEIJOO, Sánchez (Coord.). Teoría funcional de la pena y de la culpabilidad. Madrid, 2008.

MUÑOZ CONDE, F. Apéndice al libro: Grispigni, Filippo y Mezger, Edmund la reforma penal nacionalsocialista. Buenos Aires: Ediar, 2009.

MUÑOZ CONDE, F. Derecho penal y control social. Santa Fe de Bogotá: Editorial Temis, 1999.

RIVACOBA, M. Función y aplicación de la pena. Buenos Aires: Editorial Depalma, 1993.

Rivacoba, M. Introducción al estudio de los principios cardinales de derecho penal. Direito e Ciudadania n. 6, p. 57-62, 1999.

ROXIN, C. Derecho penal parte general: fundamentos: la estructura de la teoría del delito. Traducción de la $2^{a}$ edición alemana y notas por D. M. Luzón Peña, M. Díaz y García Conlledo y J. de Vicente Remesal. Madrid: Civitas, 1997. t. 1.

SILVA SÁNCHEZ, J. Del derecho abstracto al derecho real. Indret, n. 4, 2006 Disponible em: <http://www. indret.com/pdf/377_es.pdf>.

SILVA SÁNCHEZ, J. Aproximación al derecho penal contemporâneo. 2. ed. ampliada y actualizada. Buenos Aires: B de F, 2010.

SILVA SÁNCHEZ, J. Identidad en el tiempo y responsabilidad penal: el juicio jurisdiccional de imputación de responsabilidad y la identidad entre agente y acusado: estudios penales en homenaje a Enrique Gimbernat. Madrid: Edisofer, 2008. t. 2.

Solomon, R., TURNER, L. H. Y; LESSAC, M. S. Some effects of delay of punishment on resistence to temptation in dos. Journal of Personality and Social Psychology, 8, 1968.

TANNENBAUM, F. Crime and the community. New: Nueva York, 1938.

VON HIRSCH, A. Censurary castigar. Traducción de Elena Larrauri. Madrid: Trotta, 1998.

ZAFFARONI, R. Derecho penal parte general. Buenos Aires: Ediar, 2000.

ZAFFARONI, R. El enemigo en el derecho penal. Buenos Aires: Ediar, 2007.

ZAFFARONI, R. Introducción al libro: Grispigni, Filippo y Mezger, Edmund la reforma penal nacional-socialista. Buenos Aires: Ediar, 2009. 
Para publicar na revista Brasileira de Políticas Públicas, acesse o endereço eletrônico www.rbpp.uniceub.br

Observe as normas de publicação, para facilitar e agilizar o trabalho de edição. 